\title{
Correlation between Human Papillomavirus Status and Quantitative MR Imaging Parameters including Diffusion- Weighted Imaging and Texture Features in Oropharyngeal Carcinoma
}

\author{
(D) M. Ravanelli, (D)A. Grammatica, (DE. Tononcelli, (D) R. Morello, (D). Leali, (D) S. Battocchio, (D) G.M. Agazzi, \\ (D) M. Buglione di Monale e Bastia, (DR. Maroldi, DP. Nicolai, and (DD. Farina
}

\begin{abstract}
BACKGROUND AND PURPOSE: The incidence of Oropharyngeal Squampus Cell Carcinoma (OPSCC) cases is increasing especially in the Western countries due to the spreading of human papilloma virus (HPV) infection. Radiological investigations, MRI in particular, are used in the daily clinical practice to stage OPSCC. The aim of this study was to investigate the association of quantitative MR imaging features including diffusion-weighted imaging and human papillomavirus status in oropharyngeal squamous cell carcinoma.
\end{abstract}

MATERIALS AND METHODS: We retrospectively analyzed 59 patients with untreated histologically proved T2-T4 oropharyngeal squamous cell carcinoma. Human papillomavirus status was determined by viral DNA detection on tissue samples. MR imaging protocol included T2-weighted, contrast-enhanced T1-weighted (volumetric interpolated brain examination), and DWI sequences. Parametric maps of apparent diffusion coefficient were obtained from DWI sequences. Texture analysis was performed on T2 and volumetric-interpolated brain examination sequences and on ADC maps. Differences in quantitative MR imaging features between tumors positive and negative for human papillomavirus and among subgroups of patients stratified by smoking status were tested using the nonparametric Mann-Whitney $U$ test; the false discovery rate was controlled using the Benjamini-Hochberg correction; and a predictive model for human papillomavirus status was built using multivariable logistic regression.

RESULTS: Twenty-eight patients had human papillomavirus-positive oropharyngeal squamous cell carcinoma, while 31 patients had human papillomavirus-negative oropharyngeal squamous cell carcinoma. Tumors positive for human papillomavirus had a significantly lower mean ADC compared with those negative for it (median, 850.87 versus median, 1033.68; $P<.001$ ). Texture features had a lower discriminatory power for human papillomavirus status. Skewness on volumetric interpolated brain examination sequences was significantly higher in the subgroup of patients positive for human papillomavirus and smokers $(P=.003)$. A predictive model based on smoking status and mean ADC yielded a sensitivity of $83.3 \%$ and specificity $92.6 \%$ in classifying human papillomavirus status.

CONCLUSIONS: ADC is significantly lower in oropharyngeal squamous cell carcinoma positive for human papillomavirus compared with oropharyngeal squamous cell carcinoma negative for it. ADC and smoking status allowed noninvasive prediction of human papillomavirus status with a good accuracy. These results should be validated and further investigated on larger prospective studies.

ABBREVIATIONS: $\mathrm{HPV}=$ human papillomavirus; $\mathrm{OPSCC}=$ oropharyngeal squamous cell carcinoma; $\mathrm{SSF}=$ spatial scaling factor; VIBE = volumetric interpolated brain examination

O ropharyngeal squamous cell carcinoma (OPSCC) is probably the most studied head and neck neoplasm in the past decade, mainly due to the discovery of the role of human papillomavirus infection in carcinogenesis. This led to identification of a subset of patients with human papillomavirus (HPV)-positive OPSCC with

Received December 22, 2017; accepted after revision May 27, 2018.

From the Departments of Radiology (M.R., E.T., M.L., G.M.A., R.M., D.F.), Otolaryngology-Head and Neck Surgery (A.G., R.M., P.N.), Pathology (S.B.), and Radiotherapy (M.B.d.M.e.B.), University of Brescia, Brescia, Italy

Please address correspondence to Alberto Grammatica, MD, Department of Otorhinolaryngology-Head and Neck Surgery, University of Brescia, Piazza Spedali Civili 1, 25123 Brescia, Italy; e-mail: albertogrammatica@libero.it

http://dx.doi.org/10.3174/ajnr.A5792 specific demographic characteristics (younger and with fewer comorbidities) and better prognosis compared with those with HPVnegative OPSCC (usually older with more comorbidities, smokers, and alcohol consumers). ${ }^{1-4}$ Other characteristics of HPV-positive OPSCC are the high ratio between nodal and primary tumor bur$\operatorname{den}^{5}$ and the greater presence of intranodal cystic degeneration. ${ }^{6-8}$ MR imaging is routinely used for staging OPSCC in many centers. In addition to standard morphologic sequences, diffusion-weighted imaging offers an insight in tumor ultrastructure. Some recent studies have suggested that HPV-positive tumors are associated with lower apparent diffusion coefficient compared with HPV-negative ones. ${ }^{9-11}$ However, these results are equivocal. ${ }^{12}$

Texture analysis allows quantitative parameters to be ex- 


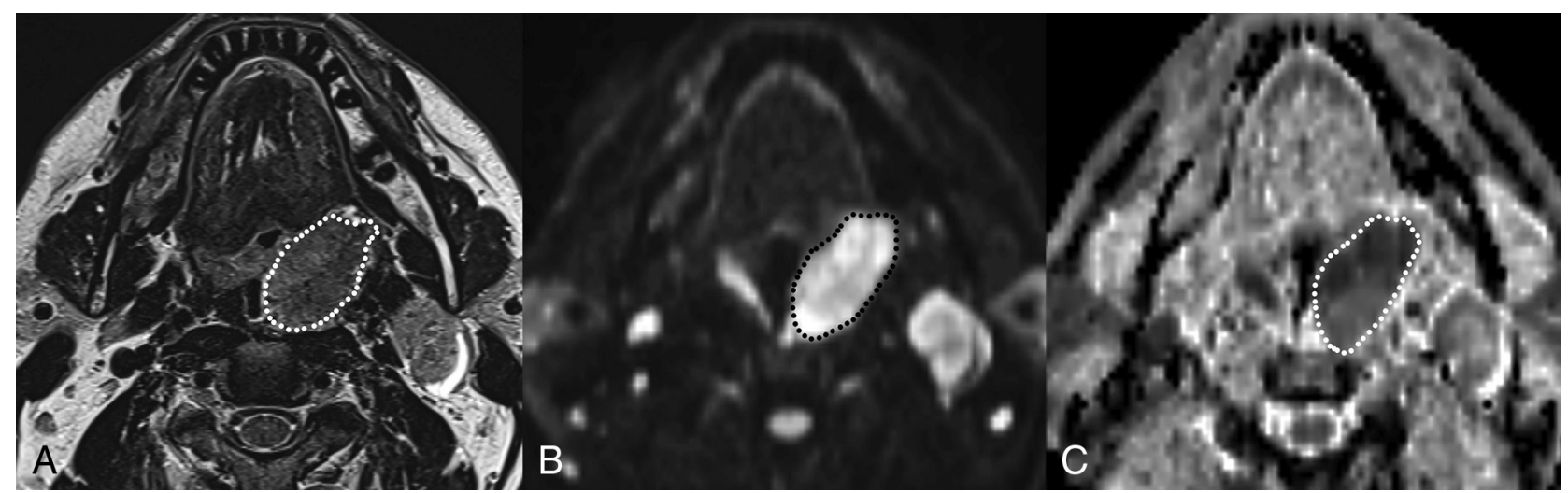

FIG 1. Example of freehand contouring of the tumor across its largest cross-sectional area on T2 ( $A$ ), $b=1000(B)$, and ADC map (C) images. Tumor segmentation on ADC maps has been helped by side-by-side visualization of other sequences, including $b=1000 \mathrm{DWI}$.

tracted from CT, MR imaging, or PET images by applying various mathematic computations and algorithms. ${ }^{13}$ The technique has been recently introduced in medical imaging research and has provided promising results for cancer prognostication ${ }^{14-19}$ and a noninvasive signature of relevant genotypic and phenotypic tumor patterns. ${ }^{20-22}$ Bogowicz et $\mathrm{al}^{23}$ recently demonstrated that a radiomic CT signature can predict HPV status in head and neck cancer, even if its accuracy was not high enough to represent a valid alternative to p16 immunohistochemistry (a surrogate biomarker) and direct viral DNA or messenger RNA studies, which remain the criterion standard. To the best of our knowledge, no study has used MR imaging texture analysis to noninvasively determine HPV status in oropharyngeal cancer. The first objective of this study was to test the correlation between ADC and HPV status on a larger and more homogeneous OPSCC sample compared with previous studies. The second objective was to investigate correlations between HPV status and a set of texture features extracted from both morphologic and DWI sequences.

\section{MATERIALS AND METHODS \\ Patients}

This retrospective study included patients with untreated histologically demonstrated T2-T4 OPSCC assessed by the Multidisciplinary Head and Neck Group of our institution between March 2010 and April 2017. HPV status was determined by direct viral DNA study on tissue samples. Pretreatment MR imaging was available for all patients. Patients with primary tumors too small to be analyzed or with a low quality of MR images due to artifacts were excluded from image analysis. Tumor, Node, Metastasis classification was performed according to the eighth edition of the TNM classification of head and neck cancer. ${ }^{24}$

\section{HPV Status Assessment}

HPV status was evaluated with the digene HC2 High-Risk HPV DNA Test (QIAGEN; https://www.qiagen.com/us/ shop/detection-solutions/human-pathogens/digene-hc2-highrisk-hpv-dna-test/\#orderinginformation), an in vitro nonradioactive nucleic acid hybridization assay with signal amplification using a chemiluminescent microtiter plate. This test is able to detect 18 HPV types, including high-risk $(16,18,31,33,35,39,45$, $51,52,56,58,59,68)$ and low-risk types $(6,11,42,43,44)$. The
Hybrid Capture 2 test shows a sensitivity and specificity equivalent to that of the polymerase chain reaction. ${ }^{25}$

\section{MR Imaging Protocol}

MR imaging was performed using a 1.5T scanner (Magnetom Aera; Siemens, Erlangen, Germany). The MR imaging protocol included: axial TSE T2 (TR, $5570 \mathrm{~ms}$; TE, $102 \mathrm{~ms}$; slice thickness, $3 \mathrm{~mm}$; matrix, $448 \times 224$ ), axial echo-planar DWI (TR, $3900 \mathrm{~ms}$; TE, $59 \mathrm{~ms}$; slice thickness, $3 \mathrm{~mm}$; matrix, $132 \times 132$ ) with b-values of 0 and $1000 \mathrm{~s} / \mathrm{mm}^{2}$, and contrast-enhanced 3D fat-saturated gradient-echo T1 (volumetric interpolated brain examination [VIBE]) with an isotropic resolution of $0.7 \mathrm{~mm}$. Apparent diffusion coefficient maps were automatically generated using an optimized noise filter.

\section{Texture Analysis}

Texture analysis was performed on primary tumors. MR images were transferred to an off-line PC and analyzed using proprietary texture analysis software TexRAD (TexRAD; Cambridge, UK). Three head and neck radiologists in consensus (M.R., M.L., E.T.), blinded to HPV status, drew an ROI on a single section of axial T2, ADC map, and postcontrast VIBE images (Fig 1), encompassing the primary tumor on its largest axial area. TexRAD software uses the filtration-histogram method as described by Miles et al. ${ }^{26}$ The filtration-histogram method comprises an initial filtration step that highlights image features of a specified size, followed by histogram analysis of the filtered image. The size of highlighted image features is denoted by the spatial scaling factor (SSF), expressed in millimeters. Histograms generated from unfiltered and filtered images were quantified by the following parameters: mean (average value of the pixels within the ROI), SD (a measure of how much variation or dispersion exists from the average), mean of positive pixels (average value of the pixels greater than zero within the ROI), entropy (a metric that reflects texture irregularity and positively correlates with tumor heterogeneity), skewness (a measure of histogram asymmetry; positive values indicate histograms skewed to the right, while negative values indicate histograms skewed to the left; skewness $=0$ indicates a perfectly symmetric histogram), and kurtosis (a measure of the peakedness of the histogram; positive kurtosis indicates a histogram that is more peaked than a Gaussian distribution, while negative kurtosis in- 
Table 1: Baseline characteristics of patients and tumors

\begin{tabular}{|c|c|c|c|c|}
\hline & Total $(n=59)$ & $\mathrm{HPV}+(n=28)$ & HPV- $(n=31)$ & $P$ Value \\
\hline Age (yr) & 64.9 & 64.4 & 65.4 & .904 \\
\hline \multicolumn{5}{|l|}{ Sex } \\
\hline Male & 43 & 19 & 24 & .413 \\
\hline Female & 16 & 9 & 7 & \\
\hline Smoker & $34 / 59$ & $8 / 28$ & $26 / 31$ & $<.0001$ \\
\hline \multirow[t]{4}{*}{ Site } & 38, Palatine tonsil & 20, Palatine tonsil & 18, Palatine tonsil & .611 \\
\hline & 17 , Tongue base & 7, Tongue base & 10 , Tongue base & \\
\hline & 3 , Soft palate & 1, Soft palate & 2 , Soft palate & \\
\hline & 1, Posterior wall & & 1, Posterior wall & \\
\hline \multicolumn{5}{|c|}{ TNM classification } \\
\hline \multirow[t]{3}{*}{$\mathrm{T}$} & $\mathrm{T} 2=25$ & $\mathrm{~T} 2=16$ & $\mathrm{~T} 2=9$ & .084 \\
\hline & $\mathrm{T} 3=2$ & $\mathrm{~T} 3=1$ & $\mathrm{~T} 3=1$ & \\
\hline & $\mathrm{T} 4=32$ & $\mathrm{~T} 4=11$ & $\mathrm{~T} 4=21(16, \mathrm{~T} 4 \mathrm{a} ; 5, \mathrm{~T} 4 \mathrm{~b})$ & \\
\hline \multirow[t]{4}{*}{$\mathrm{N}$} & $\mathrm{NO}=14$ & NO $=7$ & No $=7$ & .002 \\
\hline & $\mathrm{N} 1=15$ & $\mathrm{~N} 1=13$ & $\mathrm{~N} 1=2$ & \\
\hline & $\mathrm{N} 2=18$ & $\mathrm{~N} 2=6$ & $\mathrm{~N} 2=12(8, \mathrm{~N} 2 \mathrm{~b} ; 4, \mathrm{~N} 2 \mathrm{c})$ & \\
\hline & $\mathrm{N} 3=12$ & $\mathrm{~N} 3=2$ & $\mathrm{~N} 3=10(\mathrm{~N} 3 \mathrm{~b}=10)$ & \\
\hline \multirow[t]{2}{*}{ M } & $\mathrm{MO}=57$ & $M 0=27$ & $\mathrm{MO}=30$ & .144 \\
\hline & $M 1=2$ & $\mathrm{M} 1=1$ & $\mathrm{Ml}=1$ & \\
\hline
\end{tabular}

Note:-HPV + indicates human papillomavirus-positive; HPV - , human papillomavirus-negative.

Table 2: Quantitative MR imaging features significantly different between patients positive and negative for HPV

\begin{tabular}{|c|c|c|c|c|c|c|}
\hline \multirow[b]{2}{*}{ Variable } & \multicolumn{2}{|c|}{ HPV- } & \multicolumn{2}{|c|}{ HPV+ } & \multicolumn{2}{|c|}{$P$ Value } \\
\hline & No. & Mean & No. & Mean & Uncorrected & Corrected \\
\hline Mean ADC & 29 & 1045.2072 & 24 & 860.0675 & .000112 & .00168 \\
\hline MPP T2 SSF 4 & 31 & 149.4606 & 27 & 192.3400 & .0064 & .108 \\
\hline MPP T2 SSF 3 & 31 & 136.8981 & 27 & 173.5967 & .0072 & .108 \\
\hline Mean T2 SSF 2 & 31 & 17.6865 & 27 & 52.8400 & .0182 & .15525 \\
\hline Mean T2 SSF 3 & 31 & 34.4752 & 27 & 82.4037 & .0207 & .15525 \\
\hline Mean T2 SSF 1 & 31 & 5.8284 & 27 & 19.9081 & .031 & .1625 \\
\hline Mean T2 SSF 4 & 31 & 54.0761 & 27 & 107.7759 & .0325 & .1625 \\
\hline Kurtosis VIBE SSF 4 & 30 & 0.3773 & 26 & -0.09423 & .0358 & .446 \\
\hline
\end{tabular}

Note:-HPV - indicates human papillomavirus-negative; HPV +, human papillomavirus-positive; MPP, mean of positive pixels.

dicates that the histogram is flatter than a Gaussian distribution). In this study, SSFs of $1,2,3$, and $4 \mathrm{~mm}$ were used. A total of 30 parameters $[6 \times$ (unfiltered +4 SSF $)]$ were computed for each sequence.

\section{Statistical Analysis}

Texture parameters were compared between HPV-positive and HPV-negative groups using the Mann-Whitney $U$ or Student $t$ test (when normally distributed). The Benjamini-Hochberg correction was applied to control the false discovery rate. The $\chi^{2}$ test was used to compare categoric variables. Patients were divided in 4 subclasses, according to smoking and HPV status, which were considered as classification variables in a second step: smokers and HPV-negative (class 1), nonsmokers and HPV-positive (class 2), smokers and HPV-positive (class 3), and nonsmokers and HPV-negative (class 4). Multivariable logistic regression was used to build a predictive model for HPV status. The statistical significance level was set at $P=.05$. Statistical tests were performed using MedCalc for Windows, Version 17.8.6 (MedCalc Software, Mariakerke, Belgium).

\section{RESULTS}

Sixty-eight patients with OPSCC were enrolled; however, 4 were excluded because of the small size of the primary tumor and 5 for the low quality of MR images due to motion artifacts. Thus, 59 patients were analyzed (43 men and 16 women); 28 were HPV- positive (47\%), and 31 patients were HPV-negative (53\%). Table 1 summarizes baseline patient characteristics. Twenty-six HPVnegative lesions were found in smokers (class 1); $20 \mathrm{HPV}$-positive lesions, in nonsmokers (class 2); eight HPV-positive lesions, in smokers (class 3); and $5 \mathrm{HPV}$-negative lesions, in nonsmokers (class 4). Use of tobacco was observed in a significantly higher ratio of patients with HPV-negative OPSCC $\left(P<.0001, \chi^{2}\right.$ test). Age was not different between the 2 groups.

MR imaging texture analysis was performed on all 3 sequences (T2, DWI, and VIBE) in 50 patients. DWI was not analyzed in 5 patients (because of artifacts in 3 and because the sequence was not available in 2). The VIBE sequence was not analyzed in 3 patients ( 2 because of artifacts, 1 because the sequence was not available). In 1 patient, neither T2 nor DWI was analyzed because of low image quality.

Table 2 summarizes the texture features that were significantly associated with HPV status. Mean ADC was the parameter with the highest discriminatory power, while other parameters had significant but higher $P$ values. After Benjamini-Hochberg correction for the false discovery rate, only mean ADC maintained statistical significance. If one combined mean ADC and smoking habit in multivariable logistic regression, the resulting model allowed correctly classifying $88.2 \%$ of cases, corresponding to an area under the receiver operating characteristic curve of 0.944 (sensitivity, 83.3\%; specificity, 92.6\%) (Fig 2). When subclasses 
determined by a combination of HPV status and history of smoking were considered, some texture parameters were significantly different between class 3 (HPV-positive, smoking) and classes 1 and 2; class 4 (HPV-negative, nonsmokers) was excluded because of the very low patient numbers. In particular, patients in class 3 (HPV-positive, smokers) had a significantly higher skewness: $\mathrm{SSF}=2 \mathrm{~mm}$ on VIBE sequences compared with the other 2 classes (Table 3). This association maintained its statistical significance after Benjamini-Hochberg correction.

\section{DISCUSSION}

Our study confirms the preliminary results obtained by previous publications regarding the correlation between ADC derived from DWI and HPV status in OPSCC; finding that HPV-positive tumors had a significantly lower ADC than HPV-negative tumors. Even if the reason for this finding remains unknown, several possible explanations may be conceived. On the basis of their previous study, Driessen et $\mathrm{al}^{27}$ hypothesized that the low stromal volume observed in HPV-positive head and neck cancer could explain the cancer lower ADC. Furthermore, cancer cell nests in HPV-driven cancer are often surrounded by zones of lymphoid cells, ${ }^{28}$ which could increase tissue cell density, thus leading to lower ADC. This hypothesis is supported by a very recent pilot study published by Swartz et al, ${ }^{29}$ who found a strongly significant negative correlation between ADC and CD3-positive cell count in 20 patients with OPSCC.

In addition, HPV-positive OPSCC seems to be more fre-

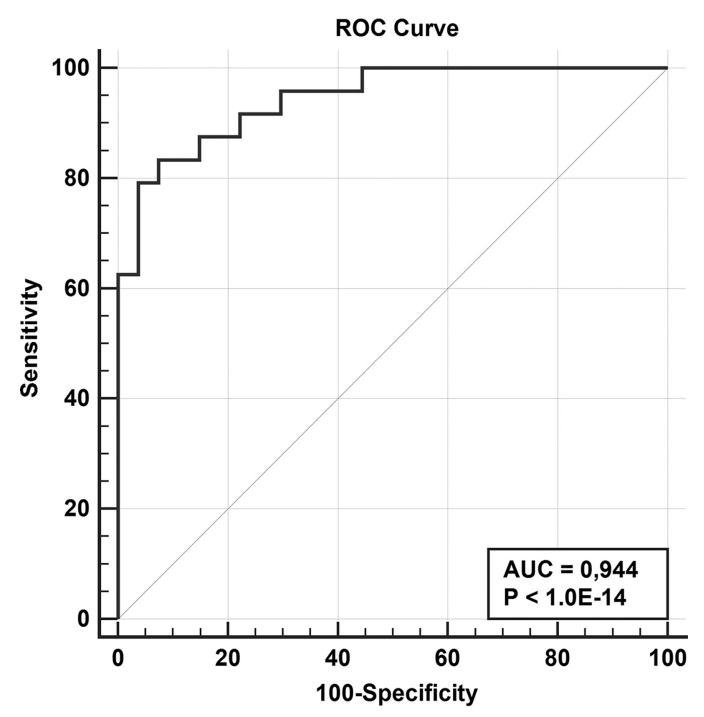

FIG 2. Receiver operating characteristic (ROC) curve of the predictive model based on mean ADC and smoking status. The classification variable was HPV status, while the variable was the predicted probability produced by multivariable logistic regression. AUC indicates area under the curve. quently associated with higher Ki-67 levels, ${ }^{30}$ which have been found to be negatively correlated to ADC in several cancer types. $^{31-35}$ The same aforementioned study by Swartz et al ${ }^{29}$ also demonstrated a negative correlation between ADC and Ki-67 expression.

The increasing evidence for the relationship between the ADC value and HPV status is relevant given that the results from several preliminary studies ${ }^{36-43}$ suggest an association between higher tumor pretreatment ADC and a poor response to chemoradiation and prognosis in head and neck cancer, though none considered HPV status in multivariable analysis. Therefore, our results emphasize the need for future studies on DWI to include HPV status as a possible important confounder for ADC in OPSCC. The present study was performed on a larger patient cohort than previous studies. ${ }^{10-12}$ The number of HPV-positive and HPV-negative tumors is better balanced (28 and 31, respectively) compared with the group analyzed by Driessen et al, ${ }^{9}$ which included only 6 HPV-positive tumors. Furthermore, the latter study included a miscellanea of head and neck cancers, while our study was selectively directed to analyze oropharyngeal cancer. Different from articles published by Chan et al, ${ }^{10}$ Nakahira et al, ${ }^{11}$ and Schouten et al, ${ }^{12}$ HPV status in our study was defined by direct viral DNA and messenger RNA studies rather than by p16 immunohistochemistry. This is an important strength because p16 immunostaining is a surrogate marker of HPV status and, despite its high sensitivity, has only moderate specificity because p16 may be constitutively activated in HPV-negative OPSCC. ${ }^{44}$ Remarkably, the absolute ADC values that we found are compellingly lower than those obtained in the previously cited studies in both HPV-positive and HPV-negative OPSCC. Even if the reason for these discrepancies cannot be fully explained, they may be conceivably imputed to differences in sequences and segmentation strategy. Kolff-Gart et $\mathrm{al}^{45}$ demonstrated that ADC values measured on different head and neck tissues differ significantly among different MR imaging systems and sequences. Juan et $\mathrm{al}^{46}$ demonstrated that non-echo-planar sequences (like those used by Schouten et $\mathrm{al}^{12}$ ) produce significantly higher ADC values for the major salivary glands compared with echo-planar sequences. Choices of different b-values and intrinsic signal-to-noise ratio might also influence ADC. Finally, ROI segmentation on $\mathrm{B}_{0}$ images (as performed by Driessen et $\mathrm{al}^{9}$ and Chan et $\mathrm{al}^{10}$ ) might include peritumoral edema, leading to increased ADC mean values.

This is the first study investigating the correlation between MR imaging texture features and HPV status in head and neck cancer. The relationship between texture parameters and HPV status was weaker than that observed between mean ADC and HPV status. Even if some parameters showed raw $P$ values $<.05$ ( 1 below .01), they lost significance after correction for the false discovery rate, which is strongly recommendable when a large number of

Table 3: Quantitative MR imaging features significantly different between patients in class 3 (HPV + and smokers) and those in classes 1 and 2 (smokers only and HPV + only, respectively)

\begin{tabular}{|c|c|c|c|c|c|c|}
\hline \multirow[b]{2}{*}{ Variable } & \multicolumn{2}{|c|}{ Class 1 or 2} & \multicolumn{2}{|c|}{ Class 3} & \multicolumn{2}{|c|}{$P$ Value } \\
\hline & No. & Mean & No. & Mean & Uncorrected & Corrected \\
\hline Skewness VIBE SSF 2 & 42 & 0.165 & 8 & 0.769 & .000798 & .02394 \\
\hline Kurtosis VIBE SSF 2 & 42 & 0.4544 & 8 & 1.4763 & .0076 & .114 \\
\hline Skewness VIBE SSF 3 & 42 & 0.1713 & 8 & 0.5788 & .0184 & .184 \\
\hline Skewness VIBE SSF 1 & 42 & 0.1119 & 8 & 0.4038 & .0364 & .273 \\
\hline
\end{tabular}


variables without a priori validation are tested. ${ }^{47}$ Conversely, a strongly significant association was found between skewness SSF $=2 \mathrm{~mm}$ (a descriptor of histogram asymmetry) on postcontrast VIBE and groups derived from the combination of HPV and tobacco smoking status. In particular, the patients in the group of HPV-positive/smokers had a significantly higher skewness when comparing the HPV-positive/nonsmoker and HPV-negative/ smoker groups. Even if this result has no obvious explanation, it is interesting in line with previous observations that the combination of HPV infection and tobacco smoking leads to a higher risk of treatment failure ${ }^{48}$ and an accumulation of genetic mutations. ${ }^{49}$

This study has some limitations. It is retrospective and based on ROIs traced on a single slice rather than on volumetric tumor analysis. Due to the relatively low number of patients, analysis of texture data did not include complex classification algorithms, which would have required both training and validation subgroups, each with sufficient numbers of patients. Thus, further information regarding relevant texture patterns could still be studied within our data. A more comprehensive approach will be adopted when our sample size reaches an adequate size. Even if the identification of a noninvasive detection method for HPV status was not the objective of the present study, the good performance of the simple regression model based on mean ADC and smoking status (which led to correct classification in $88 \%$ of cases) is an interesting result that deserves to be validated on external datasets. Furthermore, the accuracy of the model could be further improved by the addition of texture information.

\section{CONCLUSIONS}

Our study confirms the correlation between ADC derived from DWI and HPV status in OPSCC with a significantly lower ADC in HPV-positive tumors compared to HPV-negative.

Bases on these findings, we developed a simple predictive model based on ADC and smoking status that can be used as a non-invasive and cost-effective detection method for HPV status. This model deserves to be validated on external datasets and to be perfected with other parameters to increase its sensitivity.

A further noteworthy observation was that patients who are both HPV-positive and smokers have significantly higher MRI skewness, which is in line with published literature. This result does not yet have an obvious explanation and therefore would require confirmation by adding more patients and to be validated on external datasets.

\section{REFERENCES}

1. Chaturvedi AK, Engels EA, Pfeiffer RM, et al. Human papillomavirus and rising oropharyngeal cancer incidence in the United States. J Clin Oncol 2011;29:4294-301 CrossRef Medline

2. Applebaum KM, Furniss CS, Zeka A, et al. Lack of association of alcohol and tobacco with HPV16-associated head and neck cancer. J Natl Cancer Inst 2007;99:1801-10 CrossRef Medline

3. Ang KK, Harris J, Wheeler R, et al. Human papillomavirus and survival of patients with oropharyngeal cancer. N Engl J Med 2010;363: 24-35 CrossRef Medline

4. Ragin CC, Taioli E. Survival of squamous cell carcinoma of the head and neck in relation to human papillomavirus infection: review and meta-analysis. Int J Cancer 2007;121:1813-20 CrossRef Medline

5. Stenmark MH, Shumway D, Guo C, et al. Influence of human pap- illomavirus on the clinical presentation of oropharyngeal carcinoma in the United States. Laryngoscope 2017;127:2270-78 CrossRef Medline

6. Huang YH, Yeh $\mathrm{CH}$, Cheng NM, et al. Cystic nodal metastasis in patients with oropharyngeal squamous cell carcinoma receiving chemoradiotherapy: relationship with human papillomavirus status and failure patterns. PLoS One 2017;12:e180779 CrossRef Medline

7. Cantrell SC, Peck BW, Li G, et al. Differences in imaging characteristics of HPV-positive and HPV-negative oropharyngeal cancers: a blinded matched-pair analysis. AJNR Am J Neuroradiol 2013;34: 2005-09 CrossRef Medline

8. Goldenberg D, Begum S, Westra WH, et al. Cystic lymph node metastasis in patients with head and neck cancer: an HPV-associated phenomenon. Head Neck 2008;30:898-903 CrossRef Medline

9. Driessen JP, van Bemmel AJ, van Kempen PM, et al. Correlation of human papillomavirus status with apparent diffusion coefficient of diffusion-weighted MRI in head and neck squamous cell carcinomas. Head Neck 2016;38(Suppl 1):E613-18 CrossRef Medline

10. Chan MW, Higgins K, Enepekides D, et al. Radiologic differences between human papillomavirus-related and human papillomavirus-unrelated oropharyngeal carcinoma on diffusion-weighted imaging. ORL J Otorhinolaryngol Relat Spec 2016;78:344-52 CrossRef Medline

11. Nakahira M, Saito N, Yamaguchi H, et al. Use of quantitative diffusion-weighted magnetic resonance imaging to predict human papilloma virus status in patients with oropharyngeal squamous cell carcinoma. Eur Arch Otorhinolaryngol 2014;271:1219-25 CrossRef Medline

12. Schouten CS, de Graaf P, Bloemena E, et al. Quantitative diffusionweighted MRI parameters and human papillomavirus status in oropharyngeal squamous cell carcinoma. AJNR Am J Neuroradiol 2015;36:763-67 CrossRef Medline

13. Castellano G, Bonilha L, Li LM, et al. Texture analysis of medical images. Clin Radiol 2004;59:1061-69 CrossRef Medline

14. De Cecco CN, Ganeshan B, Ciolina M, et al. Texture analysis as imaging biomarker of tumoral response to neoadjuvant chemoradiotherapy in rectal cancer patients studied with 3-T magnetic resonance. Invest Radiol 2015;50:239-45 CrossRef Medline

15. Ganeshan B, Miles KA, Babikir S, et al. CT-based texture analysis potentially provides prognostic information complementary to interim FDG-PET for patients with Hodgkin's and aggressive non-Hodgkin's lymphomas. Eur Radiol 2017;27:1012-20 CrossRef Medline

16. Goh V, Ganeshan B, Nathan P, et al. Assessment of response to tyrosine kinase inhibitors in metastatic renal cell cancer: CT texture as a predictive biomarker. Radiology 2011;261:165-71 CrossRef Medline

17. Ravanelli M, Farina D, Morassi M, et al. Texture analysis of advanced non-small cell lung cancer (NSCLC) on contrast-enhanced computed tomography: prediction of the response to the first-line chemotherapy. Eur Radiol 2013;23:3450-55 CrossRef Medline

18. Smith AD, Gray MR, del Campo SM, et al. Predicting overall survival in patients with metastatic melanoma on antiangiogenic therapy and RECIST stable disease on initial posttherapy images using CT texture analysis. AJR Am J Roentgenol 2015;205:W283-93 CrossRef Medline

19. Zhang H, Graham CM, Elci O, et al. Locally advanced squamous cell carcinoma of the head and neck: CT texture and histogram analysis allow independent prediction of overall survival in patients treated with induction chemotherapy. Radiology 2013;269:801-09 CrossRef Medline

20. Aerts HJ, Velazquez ER, Leijenaar RT, et al. Decoding tumour phenotype by noninvasive imaging using a quantitative radiomics approach. Nat Commun 2014;5:4006 CrossRef Medline

21. Miles KA, Ganeshan B, Rodriguez-Justo M, et al. Multifunctional imaging signature for V-KI-RAS2 Kirsten rat sarcoma viral oncogene homolog (KRAS) mutations in colorectal cancer. J Nucl Med 2014;55:386-91 CrossRef Medline 
22. Weiss GJ, Ganeshan B, Miles KA, et al. Noninvasive image texture analysis differentiates K-ras mutation from pan-wildtype NSCLC and is prognostic. PLoS One 2014;9:e100244 CrossRef Medline

23. Bogowicz M, Riesterer O, Ikenberg K, et al. Computed tomography radiomics predicts HPV status and local tumor control after definitive radiochemotherapy in head and neck squamous cell carcinoma. Int J Radiat Oncol Biol Phys 2017;99:921-28 CrossRef Medline

24. Huang SH, O'Sullivan B. Overview of the 8th Edition TNM Classification for Head and Neck Cancer. Curr Treat Options Oncol 2017; 18:40 CrossRef Medline

25. Clavel C, Masure M, Putaud I, et al. Hybrid capture II, a new sensitive test for human papillomavirus detection: comparison with hybrid capture I and PCR results in cervical lesions. J Clin Pathol 1998; 51:737-40 CrossRef Medline

26. Miles KA, Ganeshan B, Hayball MP. CT texture analysis using the filtration-histogram method: what do the measurements mean? Cancer Imaging 2013;13:400-06 CrossRef Medline

27. Driessen JP, Caldas-Magalhaes J, Janssen LM, et al. Diffusionweighted MR imaging in laryngeal and hypopharyngeal carcinoma: association between apparent diffusion coefficient and histologic findings. Radiology 2014;272:456-63 CrossRef Medline

28. Westra WH. The morphologic profile of HPV-related head and neck squamous carcinoma: implications for diagnosis, prognosis, and clinical management. Head Neck Pathol 2012;6(Suppl 1):S48-54 CrossRef Medline

29. Swartz JE, Driessen JP, van Kempen PM, et al. Influence of tumor and microenvironment characteristics on diffusion-weighted imaging in oropharyngeal carcinoma: a pilot study. Oral Oncol 2018; 77:9-15 CrossRef Medline

30. Liu J, Zhang M, Rose B, et al. Ki67 expression has prognostic significance in relation to human papillomavirus status in oropharyngeal squamous cell carcinoma. Ann Surg Oncol 2015;22:1893-900 CrossRef Medline

31. Heijmen L, Ter Voert EE, Nagtegaal ID, et al. Diffusion-weighted MR imaging in liver metastases of colorectal cancer: reproducibility and biological validation. Eur Radiol 2013;23:748-56 CrossRef Medline

32. Schob S, Meyer J, Gawlitza M, et al. Diffusion-weighted MRI reflects proliferative activity in primary CNS lymphoma. PLoS One 2016;11: e0161386 CrossRef Medline

33. Shin JK, Kim JY. Dynamic contrast-enhanced and diffusion-weighted MRI of estrogen receptor-positive invasive breast cancers: associations between quantitative MR parameters and Ki-67 proliferation status. $J$ Magn Reson Imaging 2017;45:94-102 CrossRef Medline

34. Surov A, Gottschling S, Mawrin C, et al. Diffusion-weighted imaging in meningioma: prediction of tumor grade and association with histopathological parameters. Transl Oncol 2015;8:517-23 CrossRef Medline

35. Surov A, Stumpp P, Meyer HJ, et al. Simultaneous (18)F-FDG-PET/ MRI: associations between diffusion, glucose metabolism and histopathological parameters in patients with head and neck squamous cell carcinoma. Oral Oncol 2016;58:14-20 CrossRef Medline

36. King AD, Thoeny HC. Functional MRI for the prediction of treatment response in head and neck squamous cell carcinoma: potential and limitations. Cancer Imaging 2016;16:23 CrossRef Medline
37. Kim S, Loevner L, Quon H, et al. Diffusion-weighted magnetic resonance imaging for predicting and detecting early response to chemoradiation therapy of squamous cell carcinomas of the head and neck. Clin Cancer Res 2009;15:986-94 CrossRef Medline

38. Hatakenaka M, Shioyama Y, Nakamura K, et al. Apparent diffusion coefficient calculated with relatively high b-values correlates with local failure of head and neck squamous cell carcinoma treated with radiotherapy. AJNR Am J Neuroradiol 2011;32:1904-10 CrossRef Medline

39. Noij DP, Pouwels PJ, Ljumanovic R, et al. Predictive value of diffusionweighted imaging without and with including contrast-enhanced magnetic resonance imaging in image analysis of head and neck squamous cell carcinoma. Eur J Radiol 2015;84:108-16 CrossRef Medline

40. Ohnishi K, Shioyama Y, Hatakenaka M, et al. Prediction of local failures with a combination of pretreatment tumor volume and apparent diffusion coefficient in patients treated with definitive radiotherapy for hypopharyngeal or oropharyngeal squamous cell carcinoma. J Radiat Res 2011;52:522-30 CrossRef Medline

41. Preda L, Conte G, Bonello L, et al. Combining standardized uptake value of FDG-PET and apparent diffusion coefficient of DW-MRI improves risk stratification in head and neck squamous cell carcinoma. Eur Radiol 2016;26:4432-41 CrossRef Medline

42. Lambrecht M, Van Calster B, Vandecaveye V, et al. Integrating pretreatment diffusion weighted MRI into a multivariable prognostic model for head and neck squamous cell carcinoma. Radiother Oncol 2014;110:429-34 CrossRef Medline

43. $\mathrm{Ng} \mathrm{SH}$, Lin CY, Chan SC, et al. Clinical utility of multimodality imaging with dynamic contrast-enhanced MRI, diffusionweighted MRI, and 18F-FDG PET/CT for the prediction of neck control in oropharyngeal or hypopharyngeal squamous cell carcinoma treated with chemoradiation. PLoS One 2014;9:e115933 CrossRef Medline

44. Prigge ES, Arbyn M, von Knebel Doeberitz M, et al. Diagnostic accuracy of p16INK4a immunohistochemistry in oropharyngeal squamous cell carcinomas: a systematic review and meta-analysis. Int J Cancer 2017;140:1186-98 CrossRef Medline

45. Kolff-Gart AS, Pouwels PJ, Noij DP, et al. Diffusion-weighted imaging of the head and neck in healthy subjects: reproducibility of ADC values in different MRI systems and repeat sessions. AJNR Am J Neuroradiol 2015;36:384-90 CrossRef Medline

46. Juan CJ, Chang HC, Hsueh CJ, et al. Salivary glands: echo-planar versus PROPELLER diffusion-weighted MR imaging for assessment of ADCs. Radiology 2009;253:144-52 CrossRef Medline

47. Chalkidou A, O’Doherty MJ, Marsden PK. False discovery rates in PET and CT studies with texture features: a systematic review. PLoS One 2015;10:e0124165 CrossRef Medline

48. Maxwell JH, Kumar B, Feng FY, et al. Tobacco use in human papillomavirus-positive advanced oropharynx cancer patients related to increased risk of distant metastases and tumor recurrence. Clin Cancer Res 2010;16:1226-35 CrossRef Medline

49. Zevallos JP, Yim E, Brennan P, et al. Molecular profile of human papillomavirus-positive oropharyngeal squamous cell carcinoma stratified by smoking status. International Journal of Radiation Oncology Biology Physics 2016;94:864 CrossRef 